Open access e-Journal

Earth Science India, eISSN: $0974-8350$

Vol. 7 (III), July, 2014, pp. 67 - 72

http://www.earthscienceindia.info/

\title{
Dynamical Seasonal Prediction of Indian Summer Monsoon using AGCM: Weighted Ensemble Mean Approach
}

\author{
Sujata K. Mandke, Mahesh Shinde and A.K. Sahai \\ Indian Institute of Tropical Meteorology \\ Dr. Homi Bhabha Road, Pashan, Pune 411008, India \\ Email: amin@tropmet.res.in
}

\begin{abstract}
This study examines the fidelity of portable unified model's Atmospheric General Circulation Model in ensemble seasonal prediction of Indian Summer Monsoons of 1999-2004, driven by May SST anomaly persistent boundary conditions. Simple Ensemble-mean (EM) is inappropriate due to the presence of large deviation among the ensemble members in simulation of Indian Summer Monsoon Rainfall (ISMR). Thus 'Weighted Ensemble Mean' (WEM) method is used in the present study. In WEM method, weights are determined for all ensemble members at each model grid point using daily precipitation anomaly to distinguish the most reliable members and outliers among the ensemble members. Ensemble-mean then obtained by weighted combinations of all ensemble members is referred as 'Weighted Ensemble Mean'.

The WEM prediction of ISMR better matches with observations than EM in majority of the monsoons. Further, WEM estimated using monthly and seasonal mean weights are assessed with respect to WEM from daily mean weights. WEM with monthly/seasonal weighting is found to be similar to EM in most of the monsoons and hence daily weighting is more suited approach than monthly/seasonal weighting.
\end{abstract}

Keywords: Dynamical seasonal prediction, Indian summer monsoon, Weighted ensemble mean, Atmospheric General Circulation Model, SST persistence.

\section{Introduction}

The agriculture production and basic socio-economic needs of more than a billion people of India are significantly influenced by the vagaries of summer monsoon rainfall. Therefore, accurate prediction of seasonal monsoon rains at least one season in advance is vitally important.

The statistical methods used for Long-range Forecasts (LRF) of ISMR lacks robustness in predictor-ISMR relationship (Annamalai, 1995; Rajeevan, 2001) and thus impose limitations on fixing set of predictors (Rajeevan et al., 2004). Therefore, in recent decades, Dynamical Seasonal Prediction (DSP) using complex General Circulation Models (GCMs) provides alternative approach to statistical forecasting. Comprehensive reviews (Goddard et al., 2001; Gadgil et al., 2005) have addressed full range of issues related to both statistical and dynamical methods of LRF. 
The scientific basis for DSP is that "the source of predictability of climate beyond two weeks comes from the relatively longer timescales of variability of the lower boundary conditions" (Charney and Shukla, 1981). Atmospheric GCMs (AGCMs) in which overlying atmosphere is forced by the lower boundary conditions or coupled atmosphere-ocean GCMs (AOGCMs) with the coupled interaction of the atmosphere with the boundary conditions, are widely used to make seasonal predictions. The ensemble concept involving multiple realizations is required for DSP of Indian Summer Monsoon (ISM) because internal dynamics appear to play an important role (Sperber and Palmer, 1996; Krishnamurthy and Shukla, 2001) over this region. Several multi-model ensemble integrations with AGCMs and AOGCMs have shown the limitations in the prediction of Asian summer monsoon (Sperber et al., 2001; Wang et al., 2005; Gadgil and Srinivasan, 2011). Statistical methods have been used by the researchers to correct systematic errors/biases in the monsoon simulation (Sajani et al., 2007; Kang et al., 2004). In this context, present study is an effort to investigate the utility of WEM to improve the simple EM prediction of ISMR using AGCM.

\section{Objective}

The main aim of the study is to assess the feasibility of WEM for DSP of ISMR in research mode with Portable Unified Model (PUM) AGCM ensemble simulations. PUM AGCM's climatology and interannual variability of ISMR with observed SST forcing compare well with observations (Gadgil and Srinivasan, 2011). Thus, the PUM AGCM is suited for the study of DSP of ISMR.

\section{Design of Model Experiments}

PUM AGCM integrations are made in ensemble mode for six summer monsoons of 1999-2004. The model experiments consist of set of 12-member ensemble integrations each, for all six summer monsoon. So total model integrations of 72 summer monsoon seasons (12ensemble members*6-monsoon seasons) are performed. For a particular monsoon season, all 12-ensemble members are prescribed with the same boundary forcing of SST while differ in atmospheric initial conditions. Each ensemble member is integrated for the same length from $1^{\text {st }}$ April-30 ${ }^{\text {th }}$ September. The atmospheric states corresponding to $1^{\text {st }}$ April of 12 different years from long control integration of the same model are used as initial conditions for 12ensemble members of all six monsoon seasons. Hence, set of initial conditions for 12member ensembles are exactly identical in all summer monsoon seasons. DSP of monsoon using persisted SST anomalies (Harrison et al., 1997; Graham et al., 2000), revealed that a substantial part of the skill obtained using observed SSTs is retained even with persisted SST. Thus, observed monthly SST till May and SST anomaly of May persisted on the climatology of June-September (JJAS) is used as boundary conditions. The SST persistence is based on the assumption that SST varies slowly during the season. Monthly mean Optimum Interpolated SST (version-v2) data is used. The monsoons selected for the study are highly variable with the observed percentage departure of ISMR were $1999(-4.5 \%), 2000(-8 \%)$, 2001 (-8\%), 2002 (-19\%), 2003(+2\%) and 2004 (-13.0\%), as reported by India Meteorological Department (IMD). 
Open access e-Journal

Earth Science India, eISSN: $0974-8350$

Vol. 7 (III), July, 2014, pp. 67 - 72

http://www.earthscienceindia.info/

\section{Weighted Ensemble Mean Method}

ISMR exhibits chaotic behavior (Palmer and Anderson, 1994; Brankovic and Palmer, 2000), resulting in large dispersion among the ensemble members. Daily precipitation anomalies of 12 ensemble members simulated by PUM AGCM at an example model grid point $78^{0} \mathrm{E} ; 23^{0} \mathrm{~N}$, during $1^{\text {st }}-30^{\text {th }}$ September 2002 are shown in Fig. 1 . Large deviation is clearly visible which is particularly prominent from $17^{\text {th }}-19^{\text {th }}$ September with anomalies of opposite sign. Thus, application of WEM is explored for ISMR prediction.

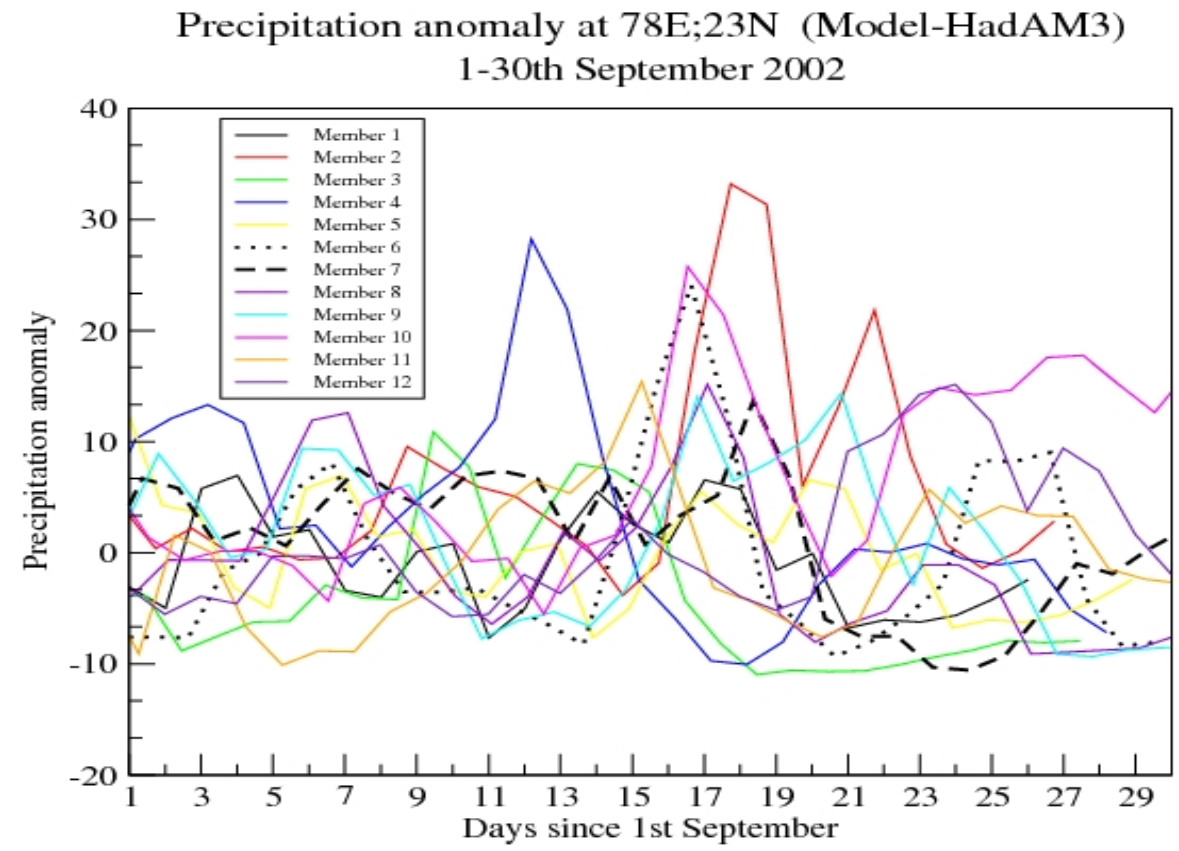

Fig. 1: Daily precipitation anomaly for September 2002 at $78^{0} \mathrm{E} ; 23^{0} \mathrm{~N}$ for 12 ensemble members simulated by PUM AGCM.

Weight for a ensemble member is determined from the inverse distance. The distance for ensemble member ' $\mathrm{j}$ ' is calculated from equation 1.

$$
\operatorname{Dist}(j)=\sum_{\substack{i=1 \\ i \neq j}}^{i=12}\left(x_{i}-x_{j}\right)^{2} \quad \text { where } \quad j=1,2,3 \ldots 12
$$

$\mathrm{X}_{\mathrm{i}}$ and $\mathrm{X}_{\mathrm{j}}$ are precipitation anomalies of $\mathrm{i}^{\text {th }}$ and $\mathrm{j}^{\text {th }}$ ensemble member respectively. The precipitation anomaly is calculated from model climatology. Weight assigned to the ensemble member is calculated from equation 2 . 
Dynamical Seasonal Prediction of Indian Summer Monsoon using AGCM: Weighted Ensemble Mean Approach: Mandke et al.

$$
w t(j)=\frac{(1 / \operatorname{dist}(j))}{\sum_{i=1}^{i=12}(1 / \operatorname{dist}(i))} \quad \text { where } \quad j=1,2,3 \ldots 12
$$

wt (j) is the weight of $j^{\text {th }}$ ensemble member. Weights are calculated for all ensemble members at each model grid points for 122-days from JJAS. The 12-member mean precipitation anomaly calculated based on the weights is referred as 'Weighted Ensembles Mean (WEM)'.

\section{Application of WEM method to Seasonal Prediction of ISM}

The performance of WEM method in DSP of ISMR is examined. The percentage departure of ISMR estimated from EM,WEM and observations for monsoons of 1999-2004 are illustrated in Fig. 2. Climate Prediction Center Merged Analysis of Precipitation (CMAP) is used as observation. The detail description of CMAP data is available in (Xie and Arkin, 1997). Figure 2 shows that WEM is closer to observations than EM for all monsoons except 2000. The results suggest that WEM is superior to EM in majority of monsoons considered in the present study.

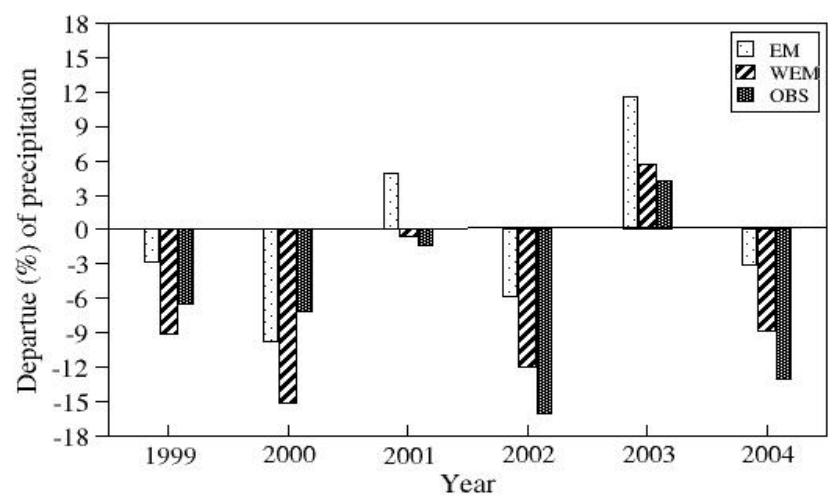

Fig. 2: Percentage departure of JJAS precipitation from EM, WEM and CMAP averaged over Indian region.

Further, the assessment of WEM estimated with the monthly and JJAS mean precipitation anomaly is carried out, in order to answer few questions such as - Is it really necessary to weight using daily anomalies?, if weights are determined using monthly/seasonal mean anomaly then would the WEM be different? The weights calculation method used is the same as that of daily weights (described in previous section 4) except using monthly/seasonal mean anomalies instead of daily anomalies.

Percentage departure of ISMR for EM, WEM with daily, monthly and seasonal weighting are illustrated together with CMAP observations in Figure 3. WEM from monthly/seasonal weighting resemble EM, while WEM from daily weighting differ largely from EM. WEM using daily weights is closer to observation in most (four out of six) of the monsoons, while WEM from monthly/seasonal weighting compare well with observation only in two monsoons. Thus it is more appropriate to use daily weighting than EM and monthly/seasonal weighting, for the selected monsoons considered in this study. 
Open access e-Journal

Earth Science India, eISSN: $0974-8350$

Vol. 7 (III), July, 2014, pp. 67 - 72

http://www.earthscienceindia.info/

$\%$ departure of JJAS precipitation over Indian region

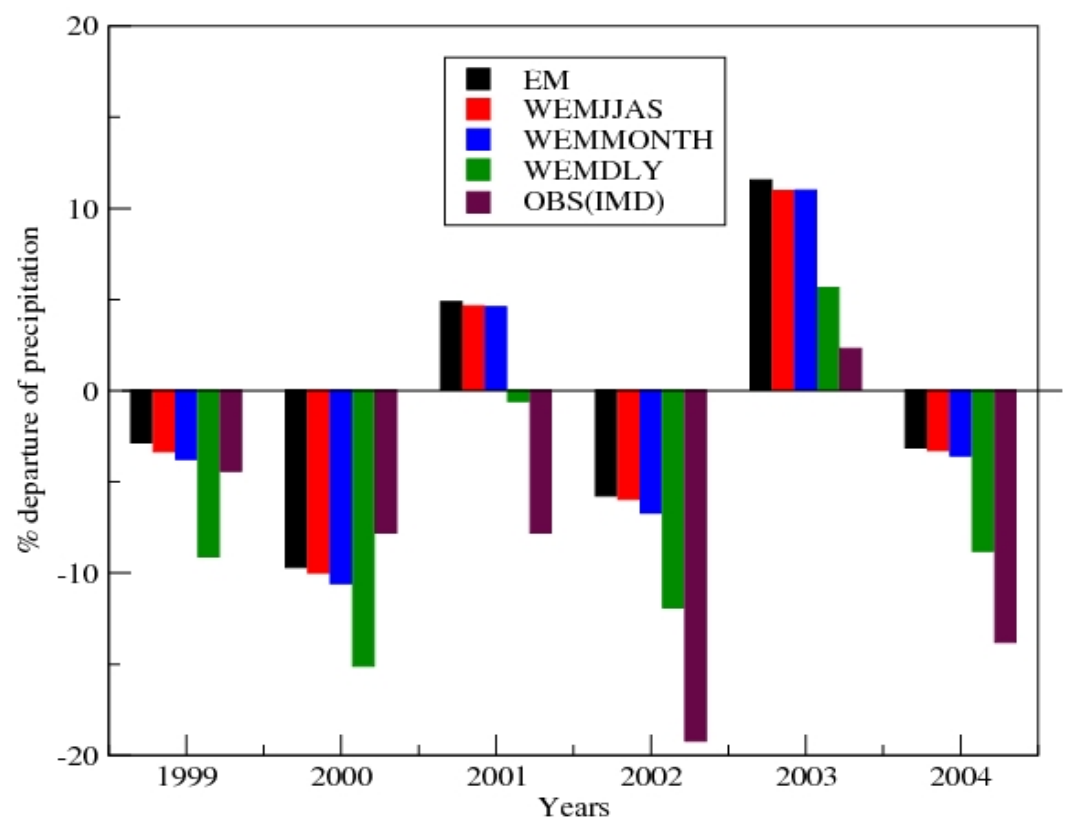

Fig. 3: Percentage departure of JJAS precipitation averaged over Indian land region indicated by separate bars for Ensemble Mean (black), WEM from seasonal mean anomaly (red), WEM from monthly mean anomaly(blue), WEM from daily anomaly (green) and IMD observation (Marroon).

\section{Concluding Remarks}

The ensemble DSP by PUM AGCM in research mode for ISMR of 1999-2004 is examined. Use of WEM method is explored due to presence of large divergence among the ensemble members. The ISMR with WEM (daily weights) is found to excel EM in majority of the monsoons considered. Further, the evaluation of WEM with weights from monthly and seasonal mean anomaly versus daily weights suggests that the daily weighting is superior to monthly/seasonal weighting.

Limitation of the study is that the results are restricted to PUM AGCM experiments of only six monsoon seasons. The systematic errors in the ISMR simulation and modeling strategy of AGCM forced by SST forcing affect the results. Thus, there is a need to examine WEM for several monsoons in multiple AOGCMs to substantiate the results obtained in the present study.

Acknowledgments: Authors would like to thank Prof. B.N, Goswami, Director, Indian Institute of Tropical Meteorology, Pune, for motivation. We acknowledge the Hadley Centre for climate prediction and research, U.K., for providing the Portable Unified Model used in the study, particularly constant support by Dr. Gill 
Martin and her colleagues from Hadley Centre for climate prediction and research, U.K. Constructive suggestions by Dr. Gill Martin have helped to improve the results. We are grateful to Mr. S.P. Gharge, Climate and Global Modeling Division, Indian Institute of Tropical Meteorology, Pune for his invaluable efforts in installation of the model on IITM computer. Grid Analysis and Display system (Grads) tool developed by Centre for Ocean Land and Atmosphere, U.S.A. and is made freely available on internet, used for visualization of data in the present study is duly acknowledged.

\section{References}

Annamalai, H. (1995) Intrinsic problems in the seasonal prediction of the Indian-summer monsoon rainfall. Meteorological and Atmospheric Physics, v. 55(1-2), pp.61-76.

Brankovic, C. and Palmer, T.N. (2000) Seasonal skill and predictability of ECMWF PROVOST ensembles. Quarterly Journal of Royal Meteorological Society, v. 126(567), pp.2035-2067.

Charney, J. G., and Shukla, J. (1981) Predictability of monsoons. In: James Lighthill and R. P. Pearce (Eds.) Monsoon Dynamics, Cambridge University Press, Cambridge, pp.99-109.

Gadgil, S., Rajeevan,M. and Nanjundiah, R. (2005) Monsoon prediction: Why yet another failure? Current Science, v. 88(9), pp.1389-1400.

Gadgil, S. and Srinivasan, J. (2011) Seasonal prediction of the Indian monsoon. Current Science, v. 100(3), pp. 343-353.

Goddard, L., Mason, S.J., Zebiak, S.E., Ropelewski,C.F., Basher, R. and Cane, M.A. (2001) Current approaches to seasonal-to-interanaual climate predictions. International Journal of Climatology, v. 21(9), pp. 1111-1152.

Graham, R.J., Evans, A.D.L., Mylne, K.R., Harrison, M.S.J. and Robertson, K.B. (2000) An assessment of seasonal predictability using atmospheric general circulation models. Quarterly Journal of Royal Meteorological Society, v. 126(567), pp.2211-2240.

Harrison, M., Soman, M.K., Davey, M., Evans, T., Robertson, K. and Ineson, S. (1997) Dynamical seasonal prediction of the Indian summer monsoon. Experimental Long-lead Forecast Bulletin, v. 6(2), pp. 2932.

Kang, I.-S., Lee, J.-Y. and Chung-Kyu Park (2004) Potential predictability of summer mean precipitation in a dynamical seasonal prediction system with systematic error correction. Journal of Climatology, v. 17 (4), pp.834-844.

Krishnamurthy, V. and J. Shukla (2001) Observed and model simulated interannual variability of the Indian monsoon. Mausam, v. 52(1), pp.133-150.

Palmer, T.N. and Anderson D. (1994) The prospect of seasonal forecasting: A review paper. Quarterly Journal of Royal Meteorological Society, v. 120(518), pp.755-793.

Rajeevan, M. (2001) Prediction of Indian summer monsoon: Status, problems and prospects. Current Science, v. $\quad$ 81(11), pp.1451-1457.

Rajeevan, M., Pai, D. S., Dikshit, S. K. and Kelkar, R. R. (2004) IMDs new operational models for long range forecast of southwest monsoon rainfall over India and their verification for 2003. Current Science, v. 86, pp. 422-431.

Sajani, S., T., Nakazawa, A., Kitoh and K., Rajendran (2007) Ensemble simulation of Indian summer monsoon rainfall by an atmospheric general circulation model. Journal of Meteorological Society of Japan, v. 85(3), pp.213-231.

Sperber, K. R. and Palmer, T. N. (1996) Interannual tropical rainfall variability in general circulation model simulations associated with the Atmospheric Model Inetrcomparison Project. Journal of Climate, v. 9(11), pp. 2727-2750.

Sperber, K. R., Brankovic, C., Deque, M., Frederiksen,C. S., Graham, R., Kitoh, A., Kobayashi,C., Palmer,T., Puri, K., Tennant,W. and Volodin, E. (2001) Dynamical seasonal predictability of the Asian summer monsoon. Monthly Weather Review, v. 129(9), pp.2226-2248.

Wang, B., Ding, Q., Fu, X., Kang, In-Sik, Jin, K., Shukla, J., and Doblas-Reyes, F. (2005) Fundamental challenge in simulation and prediction of summer monsoon rainfall. Geophysical Research Letter, v. 32(15), pp. L15711.

Xie, P., and Arkin, P.A. (1997) Global precipitation:A 17-Year monthly analysis based on gauge observations, satellite estimates and numerical model outputs. Bulletin of American Meteorological society, v. 78, pp. 2539-2558.

(Received:15.02.2014 ; Accepted:19.06.2014) 